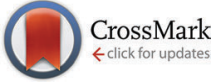

Cite this: Phys. Chem. Chem. Phys., 2017, 19, 8236

Received 21st December 2016, Accepted 1st March 2017

DOI: $10.1039 / c 6 c p 08708 f$

rsc.li/pccp

\title{
Emergence of novel hydrogen chlorides under high pressure $\dagger$
}

\begin{abstract}
Qingfeng Zeng, ${ }^{* a b}$ Shuyin $\mathrm{Yu}^{\mathrm{ab}}$ Duan $\mathrm{Li}^{\mathrm{ab}}$ Artem R. Oganov ${ }^{\mathrm{bcd}}$ and Gilles Frapper
$\mathrm{HCl}$ is a textbook example of a polar covalent molecule, and has a wide range of industrial applications. Inspired by the discovery of unexpected stable sodium and potassium chlorides, we performed systematic ab initio evolutionary searches for all stable compounds in the $\mathrm{H}-\mathrm{Cl}$ system at pressures up to $400 \mathrm{GPa}$. Besides $\mathrm{HCl}$, four new stoichiometries $\left(\mathrm{H}_{2} \mathrm{Cl}, \mathrm{H}_{3} \mathrm{Cl}, \mathrm{H}_{5} \mathrm{Cl}\right.$ and $\left.\mathrm{H}_{4} \mathrm{Cl}_{7}\right)$ are found to be stable under pressure. Our predictions substantially differ from previous theoretical studies. We evidence a high significance of zero-point energy in determining phase stability. The newly discovered compounds display a rich variety of chemical bonding characteristics. At ambient pressure, $\mathrm{H}_{2}, \mathrm{Cl}_{2}$ and $\mathrm{HCl}$ molecular crystals are formed by weak intermolecular van der Waals interactions, and adjacent $\mathrm{HCl}$ molecules connect with each other to form asymmetric zigzag chains, which become symmetric under high pressure. In $\mathrm{H}_{5} \mathrm{Cl}$, triangular $\mathrm{H}_{3}{ }^{+}$cations are stabilized by electrostatic interactions with the anionic chloride network. Further increase of pressure drives $\mathrm{H}_{2}$ dimers to combine with $\mathrm{H}_{3}{ }^{+}$cations to form $\mathrm{H}_{5}{ }^{+}$units. We also found chlorine-based Kagomé layers which are intercalated with zigzag $\mathrm{HCl}$ chains in $\mathrm{H}_{4} \mathrm{Cl}_{7}$. These findings could help to understand how varied bonding features can co-exist and evolve in one compound under extreme conditions.
\end{abstract}

\section{Introduction}

In 1935, Wigner proposed an insulator-to-metal transition in solid hydrogen under pressure. ${ }^{1}$ The dissociation, rebonding and polymeriztion, and eventual metallization of molecular systems under high pressure provide a rich ground for novel physical and chemical phenomena. Chemical bonding is the key to understanding the structures and properties of materials, and impacts a broad range of fields including physics, chemistry, biology, and materials and planetary sciences. It is known that very unusual and unexpected compounds can become stable under pressure, accompanied by a variety of bizarre topologies, and their chemical nature is still not understood. ${ }^{2,3}$ For example, under pressure, the simple $\mathrm{Na}-\mathrm{Cl}$ system contains stable

\footnotetext{
${ }^{a}$ Science and Technology on Thermostructural Composite Materials Laboratory, School of Materials Science and Engineering, Northwestern Polytechnical University, Xi'an, Shaanxi 710072, P. R. China.E-mail: qfzeng@nwpu.edu.cn ${ }^{b}$ International Center for Materials Discovery, School of Materials Science and Engineering, Northwestern Polytechnical University, Xi'an, Shaanxi 710072, P. R. China

${ }^{c}$ Department of Geosciences, Center for Materials by Design, and Institute for Advanced Computational Science, State University of New York, Stony Brook, NY 11794-2100, USA

${ }^{d}$ Moscow Institute of Physics and Technology, Dolgoprudny, Moscow Region 141700, Russia

${ }^{e}$ IC2MP UMR 7285, Université de Poitiers, CNRS, 4, rue Michel Brunet, TSA 51106, 86073 Poitiers Cedex 9, France

$\dagger$ Electronic supplementary information (ESI) available. See DOI: 10.1039/c6cp08708f
}

compounds such as $\mathrm{Na}_{3} \mathrm{Cl}, \mathrm{Na}_{2} \mathrm{Cl}, \mathrm{Na}_{3} \mathrm{Cl}_{2}, \mathrm{Na}_{4} \mathrm{Cl}_{3}, \mathrm{NaCl}_{3}$ and $\mathrm{NaCl}_{7}$, as well as 'normal' $\mathrm{NaCl}^{4,5}$

While $\mathrm{NaCl}$ is a textbook example of an ionic crystal, $\mathrm{HCl}$ is an archetypal polar covalent molecule. One can expect large differences between the $\mathrm{Na}-\mathrm{Cl}$ and $\mathrm{H}-\mathrm{Cl}$ systems; however, we can imagine the $\mathrm{H}-\mathrm{Cl}$ system to be even more diverse due to its increased variety of intermolecular and intramolecular interactions. In addition, hydrogen adds extra excitement: the high-pressure metallic phase of hydrogen has been predicted to possess a nearly room-temperature superconductivity $\left(T_{\mathrm{c}} \sim 240 \mathrm{~K}\right){ }^{6}{ }^{6}$ while superconducting metallic hydrogen remains elusive. In 2014, an unusual stoichiometry, $\mathrm{H}_{3} \mathrm{~S}$, was predicted with a high- $T_{\mathrm{c}}$ reaching $\sim 200 \mathrm{~K}$ at $200 \mathrm{GPa}^{7}$ Later, Eremets et al. verified that the phase responsible for high- $T_{\mathrm{c}}$ superconductivity (203 $\mathrm{K}$ ) in the sulfur hydride system is $\mathrm{H}_{3} \mathrm{~S}^{8}$ It has been suggested that alloying hydrogen with other elements can greatly reduce the pressure required for stability of the superconducting state, ${ }^{9}$ and one may think not of only metal hydrides, but also of compounds with more electronegative atoms, such as the aforementioned $\mathrm{H}_{3} \mathrm{~S}$, or the $\mathrm{H}_{n} \mathrm{Cl}$ compounds studied here.

For the $\mathrm{H}-\mathrm{Cl}$ system, $\mathrm{HCl}$ has been extensively studied in the past few decades. ${ }^{10-13}$ At very low temperatures, $\mathrm{HCl}$ adopts an ordered orthorhombic $C m c 2_{1}$ structure, which is also adopted by $\mathrm{HBr}$ and $\mathrm{HF} .{ }^{11}$ With increasing pressure, the $C m c 2_{1}$ phase was suggested to transform into another orthorhombic $\mathrm{Cmcm}$ structure at $51 \mathrm{GPa}$ with hydrogen bond symmetrization. ${ }^{14}$ The Cmcm phase is stable until $108 \mathrm{GPa},{ }^{11}$ then a post- $\mathrm{Cmcm}$ phase 
with space group $P \overline{1}$ appears. However, at pressures higher than $230 \mathrm{GPa}$, the stability of $\mathrm{HCl}$ remains controversial. Duan et $a l .{ }^{15}$ predicted that the $P 2_{1} / m$ structure would be the most stable one for $\mathrm{HCl}$ above $233 \mathrm{GPa}$, while a recent work by Chen et al. $^{12}$ proposed $\mathrm{C} 2 / \mathrm{m}$ and $P 4 / \mathrm{nmm}$ structures, which are more stable than $P 2_{1} / m$ above $250 \mathrm{GPa}$. Furthermore, the calculated enthalpy difference between $C 2 / \mathrm{m}$ and $P 4 / \mathrm{nmm}$ phases was negligibly small above $250 \mathrm{GPa}$. However, we know that zeropoint energy (ZPE) usually plays a non-negligible role in the total energy of low-atomic-mass materials, and this effect was not considered in previous studies of the $\mathrm{H}-\mathrm{Cl}$ system.

Besides $\mathrm{HCl}$, several $\mathrm{H}_{x} \mathrm{Cl}_{y}$ compounds have also been predicted. ${ }^{15,16}$ In 2015 , Wang et al. ${ }^{16}$ studied the crystal structures and phase stabilities of the hydrogen-rich $\mathrm{H}_{2}-\mathrm{HCl}$ system by using a first-principles particle-swarm CALYPSO code. Between 100-300 GPa, two stable compounds with $\mathrm{H}_{5} \mathrm{Cl}$ and $\mathrm{H}_{2} \mathrm{Cl}$ stoichiometries were found. In $\mathrm{H}_{5} \mathrm{Cl}$, they found the stabilization of cationic $\mathrm{H}_{3}{ }^{+}$species. It becomes almost an equilateral triangle under very high pressure. Soon after, Duan et al. ${ }^{17}$ reexamined the phase stabilities of the $\mathrm{H}_{2}-\mathrm{HCl}$ system by using the same CALYPSO code. However, very different results were found in their study. Besides $\mathrm{H}_{5} \mathrm{Cl}$ and $\mathrm{H}_{2} \mathrm{Cl}$, Duan et al. found that $\mathrm{H}_{3} \mathrm{Cl}$ and $\mathrm{H}_{7} \mathrm{Cl}$ could also be stabilized in the pressure range of 0-250 GPa, which is in contradiction with the results of Wang et al. ${ }^{16}$ in which they found the very same two stoichiometries to be metastable up to $300 \mathrm{GPa}$. In the above two studies, their reactants are $\mathrm{H}_{2}$ and $\mathrm{HCl}$, thus the stabilities of the chlorine-rich phases in the full $\mathrm{H}-\mathrm{Cl}$ system are still unclear. The question of whether a chlorine-rich structure can be stabilized under high pressure is still unresolved. Here, we apply a powerful evolutionary algorithm, USPEX, to extensively explore the crystal structures and stoichiometries in the $\mathrm{H}-\mathrm{Cl}$ system. We attempt to give an exhaustive picture of the $\mathrm{H}-\mathrm{Cl}$ system under pressure.

\section{Methods}

Searches for stable compounds in the $\mathrm{H}-\mathrm{Cl}$ system from ambient pressure up to $400 \mathrm{GPa}$ were performed using the variablecomposition $a b$ initio evolutionary algorithm USPEX. ${ }^{18-20}$ In these searches, all $\mathrm{H}_{x} \mathrm{Cl}_{y}$ compositions were allowed, under the constraint that the total number of atoms in the primitive cell could be up to 30 atoms. The first generation contained 100 candidate structures, while all subsequent generations contained 80 structures. In each new generation, $40 \%$ of the structures were produced by heredity, $20 \%$ by softmutation, $20 \%$ by transmutation and $20 \%$ were produced randomly.

Local geometry relaxations were performed using density functional theory calculations with the use of VASP code. $^{21}$ These calculations are based on the Perdew-Burke-Ernzerhof (PBE) functional, ${ }^{22}$ which belongs to the generalized gradient approximation (GGA) level of theory. We used the all-electron projector-augmented wave (PAW) method, ${ }^{23,24}$ with the outermost core radius of $1.1 \mathrm{a} . \mathrm{u}$. for the $\mathrm{H}$ atom and $1.9 \mathrm{a}$.u. for the $\mathrm{Cl}$ atom. The plane-wave kinetic energy cutoff was set to $900 \mathrm{eV}$, and uniform $\Gamma$-centered $k$-meshes with a reciprocal space resolution of $2 \pi \times 0.03 \AA^{-1}$ were used for sampling the Brillouin zone. These settings enabled excellent convergence of the energy differences, stress tensors, and structural parameters. Phonon spectra were calculated using the finite-displacement method as implemented in the PHONOPY package ${ }^{25}$ in order to probe the dynamical stability and explore the effects of ZPE on the thermodynamic stability of $\mathrm{H}_{x} \mathrm{Cl}_{y}$ compounds (see the ESI $\dagger$ ).

All molecular species were optimized at different levels of theory (B3PW91, PBE, MP2, CCSD). A triple-zeta basis set was employed for all atoms, which was increased using both polarized and diffuse functions, aug-cc-pVTZ. ${ }^{2,27}$ For each structure, the analytic Hessian was calculated to obtain the vibrational frequencies and determine the nature of the stationary point. These calculations were performed using the Gaussian package. ${ }^{28}$ As the results followed the same trend, we present here only the electrostatic potential results based on the B3PW91 functional. The surface potentials, $V_{\mathrm{s}}(r)$, were obtained using the Wave Function Analysis-Surface Analysis Suite (WFA). ${ }^{29}$

\section{Results and discussion}

The calculated convex hulls and pressure-composition phase diagram taking into account the vibrational contributions (ZPE) of the $\mathrm{H}-\mathrm{Cl}$ system are shown in Fig. 1. The enthalpies of formation of the $\mathrm{H}_{x} \mathrm{Cl}_{y}$ phases have been calculated with respect to elemental hydrogen and chlorine in their most stable forms, i.e., $\mathrm{P6}_{3} / \mathrm{m}, \mathrm{C2} / \mathrm{c}$, Cmcā̄2, Cmca and $I 4_{1} /$ amd structures for hydrogen, ${ }^{30}$ and Cmca, Fmm2, Immm and fcc structures for chlorine ${ }^{31}$ in their stability fields. The convex hull is a set of thermodynamically stable states, which are stable with respect to disproportion into other phases or pure elements. Any structure, for which the enthalpy of formation lies on the convex hull, is considered to be thermodynamically stable and in principle can be synthesized from any isochemical mixture.

Besides reproducing the well-known $\mathrm{HCl}$, we also found the stable stoichiometries $5: 1,3: 1,2: 1$ and $4: 7$. It can be seen

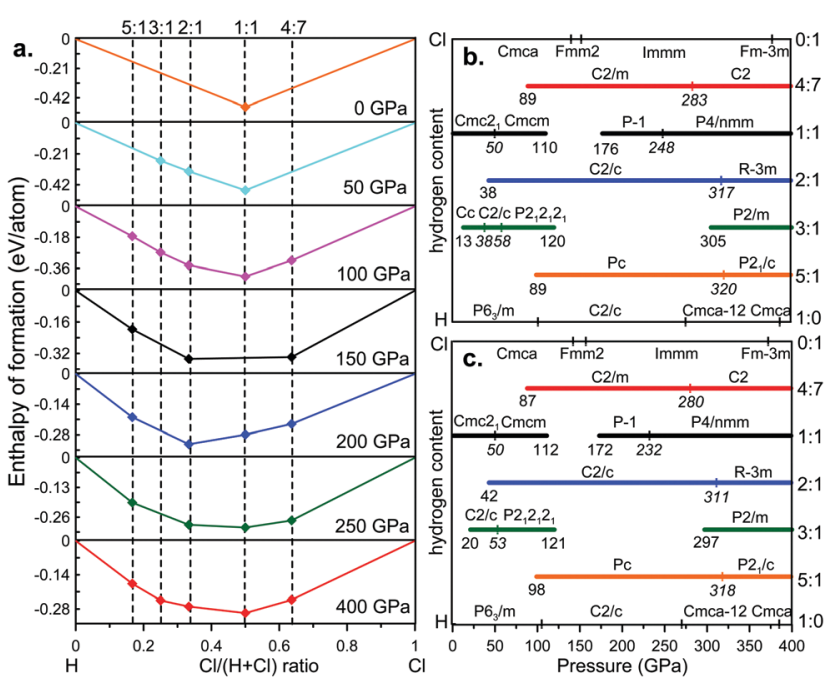

Fig. 1 (a) The calculated convex hulls of the $\mathrm{H}-\mathrm{Cl}$ system at selected pressures. ( $b$ and $c$ ) Pressure-composition phase diagram of the $\mathrm{H}-\mathrm{Cl}$ system between 0 and $400 \mathrm{GPa}$ without (b) and with (c) ZPE corrections. 
that $\mathrm{HCl}$ remains a stable compound in the pressure ranges of 0-112 GPa and 172-400 GPa, but between them, it will decompose into $\mathrm{H}_{2} \mathrm{Cl}$ and $\mathrm{H}_{4} \mathrm{Cl}_{7}$. $\mathrm{HCl}$ is predicted to adopt four phases with the space groups $C m c 2_{1}$ (0-50 GPa), Cmcm (50-112 GPa), $P \overline{1}$ (172-232 GPa) and $P 4 / \mathrm{nmm}$ (232-400 GPa). For the low-pressure $\mathrm{Cmc2}_{1}$ and $\mathrm{Cmcm}$ phases, their enthalpies are indistinguishable above $50 \mathrm{GPa}$, due to the very similar structures. However, we find that hydrogen bond symmetrization occurs at around $50 \mathrm{GPa}$, consistent with previous studies. ${ }^{11,12,16,17}$ After considering ZPE correction, the $P \overline{1}$ phase transforms into the $P 4 / \mathrm{nmm}$ phase at $232 \mathrm{GPa}$ instead of $250 \mathrm{GPa}^{12}$ proposed by Chen et $a .^{12}$ Besides, the $P 4 / \mathrm{nmm}$ phase has a slightly lower enthalpy than the $C 2 / m$ structure. ${ }^{12}$

For $\mathrm{H}_{7} \mathrm{Cl}$ discovered in the work of Duan et al. ${ }^{17}$ (see Fig. S2, ESI $\dagger$ ), we found it is metastable with or without considering the ZPE correction. For $\mathrm{H}_{5} \mathrm{Cl}$, our evolutionary searches revealed a new structure with the space group $P c$ at low pressures, which has a slightly lower energy than the previously proposed $C c$ structure $^{16,17}(\sim 6 \mathrm{meV}$ per atom at $150 \mathrm{GPa})$. At $318 \mathrm{GPa}$, the $P c$ phase transforms into a new structure with the space group $P 2_{1} / c$. For $\mathrm{H}_{3} \mathrm{Cl}$, it emerges on the phase diagram at $20 \mathrm{GPa}$ and decomposes into $\mathrm{H}_{2} \mathrm{Cl}$ and $\mathrm{H}_{5} \mathrm{Cl}$ at $121 \mathrm{GPa}$ and reappears at $297 \mathrm{GPa}$, which is consistent with the results of Duan et al. ${ }^{17}$ In their work, three phases with space groups $C c(12-40 \mathrm{GPa}), C 2 / c$ (40-60 GPa), and $P 2{ }_{1} 2_{1} 2_{1}(60-120 \mathrm{GPa})^{17}$ were predicted (see Fig. S2, ESI $\dagger$ ). However, when ZPE is taken into account, the $C 2 / c$ structure has a lower energy $(\sim 7 \mathrm{meV}$ per atom at $25 \mathrm{GPa})$ and becomes more stable than the $C c$ structure. The transition pressure from $C 2 / c$ to $P 2_{1} 2_{1} 2_{1}$ becomes $53 \mathrm{GPa}$ instead of $60 \mathrm{GPa}$. For $\mathrm{H}_{2} \mathrm{Cl}$, the monoclinic $C 2 / c$ structure appears at $42 \mathrm{GPa}$ and transforms to the highly-symmetric $R \overline{3} \mathrm{~m}$ structure at $311 \mathrm{GPa}$. Remarkably, we found a new chlorine-rich compound $\mathrm{H}_{4} \mathrm{Cl}_{7}$, which becomes stable at $87 \mathrm{GPa}$ and remains stable up to $400 \mathrm{GPa}$.

Detailed lattice parameters and atomic Wyckoff positions of these thermodynamically stable $\mathrm{H}_{x} \mathrm{Cl}_{y}$ phases are given in Table S1 (ESI $\dagger$ ). Their calculated phonon spectra displayed in Fig. S3 (ESI $\dagger$ ) confirm that all these compounds are dynamically stable with no imaginary phonon modes in the whole Brillouin zone. After analyzing their crystal structures, we identified a rich variety of structural features, such as asymmetric or symmetric zigzag $\mathrm{HCl}$ chains, host-guest inclusion compounds, chlorinebased Kagomé layers, hcp chlorine network with interstitial protons and stretched $\mathrm{H}_{2}$ units, one-dimensional (1D) hydrogen chains, bridging $\mathrm{H}_{3}{ }^{+}$and $\mathrm{H}_{5}{ }^{+}$units, interpenetrating graphenelike chlorine nets and others, which will be illustrated below.

\subsection{HCl: a brief revisit of the pressure-induced symmetrization of the zigzag chains}

At ambient conditions, $\mathrm{HCl}$ adopts the orthorhombic $C m c 2_{1}$ structure, which remains stable up to $50 \mathrm{GPa}$ (Fig. 2a). In this structure, $\mathrm{HCl}$ forms zigzag chains with a $\mathrm{H}-\mathrm{Cl}$ distance of $1.313 \AA$, compared with the calculated $\mathrm{H}-\mathrm{Cl}$ bond length of $1.311 \AA$ in the gas phase (exp. 1.274 $\AA$ ). The intermolecular $\mathrm{H}-\mathrm{Cl}$ separations in $C m c 2_{1}$ are $2.219 \AA$, much less than the sum of the van der Waals radii of $2.950 \AA^{32}$ and typical of $\mathrm{H} \cdots \mathrm{Cl}$ a.

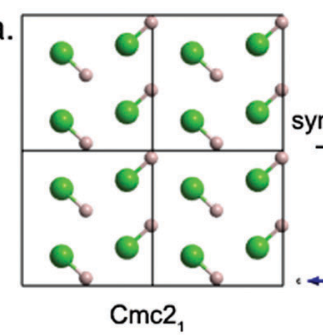

C.

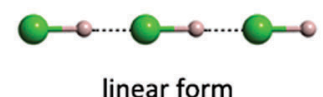

or

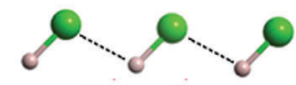

all trans form

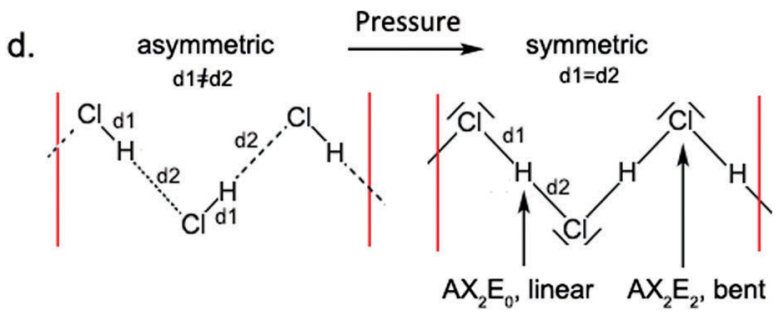

Fig. 2 (a and b) Crystal structures of $\mathrm{Cmc2}_{1}$ - and $\mathrm{Cmcm}-\mathrm{HCl}$. The big green spheres represent $\mathrm{Cl}$ atoms, while the small pink ones denote $\mathrm{H}$ atoms. (c) $1 \mathrm{D}$ planar $\mathrm{HCl}$ chain in linear and all-trans forms. (d) Lewis structure for the 1D symmetrized zigzag chain with VSEPR $A_{n} E_{m}$ notation.

hydrogen bonds. In the next $\mathrm{Cmcm}$ phase, $\mathrm{HCl} \cdots \mathrm{HCl}$ contacts have an L-shaped geometry, with the $\mathrm{H}-\mathrm{Cl}$ bond axis of one molecule perpendicular to the other one. A similar herringbone pattern is also observed in solid $\mathrm{X}_{2}$ (X, halogen). ${ }^{33,34}$ Why does the $\mathrm{HCl}$ chain possesses a zigzag shape (L-shaped geometry) rather than a linear or all-trans one (Fig. 2c)? Electrostatic arguments can be used to find the answer (Fig. 3).

The computed electrostatic potential $V_{\mathrm{s}}(r)$ on the 0.001 a.u. surface of $\mathrm{HCl}$ is displayed in Fig. 3. A region of positive electrostatic potential - the so-called $\sigma$-hole ${ }^{35,36}$ - can be seen on the outer surface of the hydrogen, with a maximum positive $V_{\text {s,max }}$ value of $44.6 \mathrm{kcal} \mathrm{mol}^{-1}$. Due to the two chlorine lone pairs of electrons in the $3 \mathrm{p}_{x}$ and $3 \mathrm{p}_{y}$ orbitals, the most negative values $V_{\mathrm{s} \text {, min }}$ are on the lateral rings of the chlorine negative potential surface, shown in red with a $V_{\mathrm{s}, \max }$ of $-9.5 \mathrm{kcal} \mathrm{mol}^{-1}$. Thus, the hydrogen atom may be considered as a Lewis acid site,
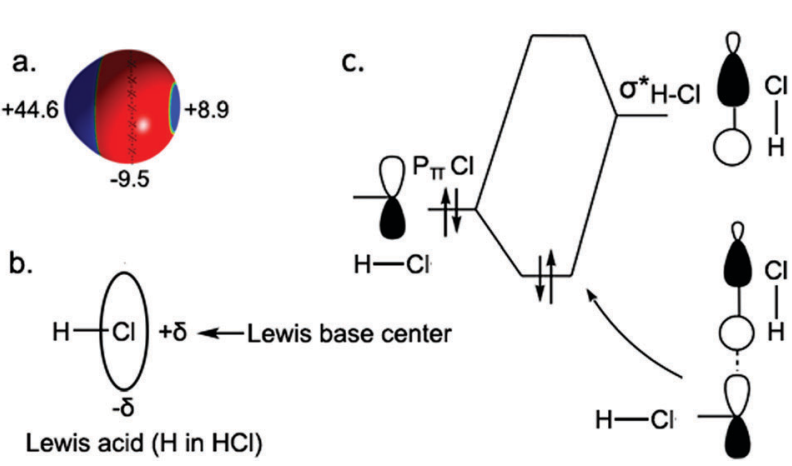

b.

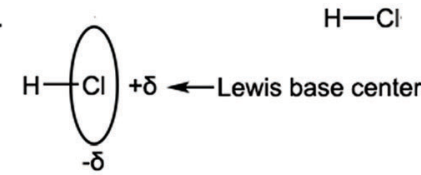

Lewis acid $(\mathrm{H}$ in $\mathrm{HCl})$

Fig. 3 (a) The computed electrostatic potential on the molecular surface of a $\mathrm{HCl}$ dimer. (b) Schematic $\sigma$-hole concept for hydrogen and halogen bonds. (c) Orbital interaction diagram of $\mathrm{HCl}$... HCl dimer in an L-shaped coordination. 
and the halogen atom interacts as an electron donor through its $\pi$ lone pairs, thus the angle for the $\mathrm{H} \cdots \mathrm{Cl}-\mathrm{H}$ arrangement should be around $90^{\circ}$, therefore the linear form is rejected. Moreover, to understand why the L-shaped coordination $\left(\mathrm{Cl} \cdots \mathrm{H}-\mathrm{Cl}=180^{\circ}\right)$ is preferred to the all-trans one $\left(\mathrm{Cl} \cdots \mathrm{H}-\mathrm{Cl}=90^{\circ}\right)$, molecular orbital arguments can be used. As depicted in Fig. 3c, the bonding interaction between the filled $\mathrm{p}_{\pi}(\mathrm{Cl})$ orbital - a lone pair of $\mathrm{Cl}$ - of an $\mathrm{HCl}$ unit and the vacant $\sigma_{\mathrm{H}-\mathrm{Cl}}{ }^{*}$ level of the other is optimized when the $\mathrm{Cl} \cdots \mathrm{H}-\mathrm{Cl}$ angle is $180^{\circ}$ (Fig. 3c). This two-electron stabilizing interaction and the anisotropy of the electron charge distribution of the halogen $(\mathrm{Cl})$ atom explain why the $\mathrm{HCl}$ chain possesses an L-shaped geometry.

To summarize, this zigzag topology is closely related to the anisotropy of the electron charge distribution of the halogen (Cl) atom. A stabilizing interaction between two $\mathrm{H}-\mathrm{Cl}$ units occurs in such a manner that a filled $\mathrm{Cl}-\mathrm{p}_{\pi}$ orbital $-\mathrm{a} \pi$ lone pair of $\mathrm{Cl} \mathrm{-} \mathrm{is} \mathrm{oriented} \mathrm{towards} \mathrm{the} \mathrm{H}-\mathrm{Cl}$ bond of the other. Eventually, symmetric hydrogen bonds appear. These symmetric HCl-based zigzag chains are also encountered in other phases at different compositions. ${ }^{11,14,37}$ In the $\mathrm{Cmcm}$ phase at $100 \mathrm{GPa}$, symmetric zigzag chains are stacked along the $a$-axis with an interchain spacing of $1.940 \AA$ and a shortest $\mathrm{Cl}-\mathrm{Cl}$ separation of $2.883 \AA$ A. Delocalized three-center two-electron bonding is expected along the $\sigma \mathrm{H}-\mathrm{Cl}$ chains, which explains the increase in the covalent $\mathrm{H}-\mathrm{Cl}$ bond length from $1.313 \AA$ at $0 \mathrm{GPa}$ to $1.442 \AA$ at $100 \mathrm{GPa}$, and the decrease in the hydrogen-bond separation to $2.219 \AA$ at $0 \mathrm{GPa}$. In agreement with the VSEPR model, here the zigzag chain contains chlorine atoms in a bent two-coordinate configuration ( $\mathrm{H}-\mathrm{Cl}-\mathrm{H}$ angle of $84.2^{\circ}$ ) and two-coordinate almost linear hydrogen atoms (Fig. 2d and Fig. S4, ESI $\dagger$ ).

The hydrogen bond symmetrization/desymmetrization process for $\mathrm{HCl}$ chains under high pressure is well characterized, ${ }^{38}$ and can be considered as a classical example of a second-order Peierls distortion in weakly 1D covalent dimer-based chains. The symmetric zigzag $\mathrm{HCl}$ chain displays Peierls-type instability of the $\sigma$-bands at the Fermi level, which induces a structural distortion along the $\sigma \mathrm{H}-\mathrm{Cl}$ backbone - creation of short and long $\mathrm{H}-\mathrm{Cl}$ bonds - when the pressure is reduced to ambient conditions. This dimerization process leads to the thermodynamically stable covalent $\mathrm{HCl}$ monomers. Finally, in addition to hydrogen bond symmetrization, reduction of the van der Waals volume occurs under compression, leading to stronger interchain $\mathrm{Cl}-\mathrm{Cl}$ interactions. From 0 to $100 \mathrm{GPa}$, the interplane $\pi$ stacking separation decreases drastically from $3.506 \AA$ to $1.940 \AA$ A, respectively, while the interplane $\sigma$ stacking $\mathrm{Cl}-\mathrm{Cl}$ separation decreases from $4.024 \AA$ to $2.514 \AA$. This effect leads to band gap closure upon compression (Fig. S5, ESI $\dagger$ ).

For the high-pressure $\mathrm{HCl}$ phases, our structure searches revealed the triclinic $P \overline{1}$ structure as the most stable one at $150 \mathrm{GPa}$. The $P \overline{1}$ structure contains four $\mathrm{H}-\mathrm{Cl}$ molecules in the unit cell and only possesses the space-inversion symmetry. Note that the zigzag $\mathrm{H}-\mathrm{Cl}$ chains discovered in the $\mathrm{Cmc2}_{1}$ and $\mathrm{Cmcm}$ phases collapse in the $P \overline{1}$ phase instead of forming the intriguing distorted squares, where the chlorine atoms are connected by asymmetric hydrogen bonds. The tetragonal $P 4 / \mathrm{nmm}$ structure becomes stable at pressures above $232 \mathrm{GPa}$ upon considering the ZPE effect. P4/nmm $\mathrm{HCl}$ possesses a layered mackinawitetype structure, and adjacent $\mathrm{HCl}$-based zigzag chains get close to form 2D layers. The shortest interlayer $\mathrm{Cl}-\mathrm{Cl}$ distance is $2.199 \AA$ at $300 \mathrm{GPa}$. In each layer, $\mathrm{HCl}$ zigzag chains run along the $a$ - and $b$-axes. Here, hydrogen atoms have a distorted tetrahedral coordination ( $\mathrm{Cl}-\mathrm{H}-\mathrm{Cl}$ angle of $126.7^{\circ}$ ), while chlorine atoms have a four-fold umbrella coordination, using the interlayer space to contain lone electron pairs. The increased $\mathrm{H}-\mathrm{Cl}$ bond length reflects the increase in the number of $\mathrm{H}-\mathrm{Cl}$ bonds under compression - four in $P 4 / \mathrm{nmm}(1.574 \AA$ at $300 \mathrm{GPa})$, two in symmetric $\mathrm{Cmcm} \mathrm{HCl}(1.442 \AA$ at $100 \mathrm{GPa})$, one in molecular $C m c 2_{1}(1.313 \AA$ at $0 \mathrm{GPa})$ - reflecting electron delocalization in the covalent $2 \mathrm{D}$ layers of the highest-pressure $P 4 / \mathrm{nmm}$ phase.

\section{2 $\mathrm{H}_{2} \mathrm{Cl}$ and $\mathrm{H}_{3} \mathrm{Cl}$ : $\mathrm{HCl}$ zigzag chains $+\mathrm{H}_{2}$ units}

The hydrogen-rich compound $\mathrm{H}_{2} \mathrm{Cl}$ crystallizes in the monoclinic $C 2 / c$ structure (Fig. 4a). This structure is formed by planar symmetric zigzag $\mathrm{HCl}$ chains and $\mathrm{H}_{2}$ dimers. $\mathrm{H}_{2}$ dimers also form planar zigzag chains with alternating short intramolecular $(0.733 \AA$ at $100 \mathrm{GPa})$ and long intermolecular $(1.563 \AA$ at $100 \mathrm{GPa}$ ) distances. As expected from band theory (Peierls distortion), this encapsulated $\left(\mathrm{H}_{2}\right)_{n}$ chain is insulating and presents yet another classical textbook hydrogen chain model in an experimentally synthesizable material. Pairs of stacked $\mathrm{HCl}$ chains are observed in the ac planes. A shortest $\mathrm{Cl}-\mathrm{Cl}$ separation of $2.496 \AA$ is found, compared to the van der Waals Cl-Cl separation of $3.50 \AA$ at 0 GPa. Thus, some attractive interactions are at work in these paired chains, a signature of the chain-pairing effect.

At $311 \mathrm{GPa}$, the low-pressure $C 2 / c$ structure transforms to a previously omitted ${ }^{16}$ rhombohedral $R \overline{3} m$ structure (Fig. 4b), which has a cubic close packing of $\mathrm{Cl}$ atoms in which all octahedral voids are filled by $\mathrm{H}_{2}$ groups. The $\mathrm{H}-\mathrm{H}$ distance $(1.057 \AA)$ is much longer than that of the $\mathrm{H}_{2}$ molecule $(0.74 \AA)$, though still bonding, which indicates weakening due to depletion of the $\sigma$-bonding orbital that donates part of its electron to the $\mathrm{Cl}$ framework. The band structure of the $R \overline{3} \mathrm{~m}$ phase displays a 'flat band-steep band' character ${ }^{39}$ (Fig. S6, ESI $\dagger$ ), suggesting potential superconductivity. The electron-phonon coupling (EPC) calculation shows that the EPC constant $\lambda$ is 0.66 with an $\omega_{\log }$ of $1368 \mathrm{~K}$ at $400 \mathrm{GPa}$. By using the Allen-Dynes modified McMillan equation, ${ }^{40}$ we obtained the superconducting transition temperature $\left(T_{\mathrm{c}}\right)$ of 43.9-44.8 K $\left(\mu^{*}=0.1-0.13\right)$. Also, we found that coupling of the electrons to hydrogen vibrations in the frequency region of 33-60 THz contributes $\sim 64.1 \%$ of the total $\lambda$. (a)

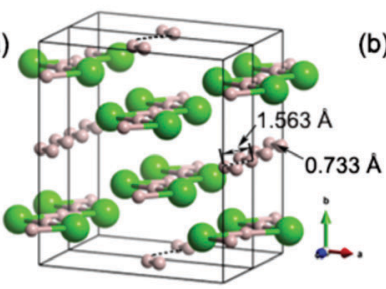

(b)

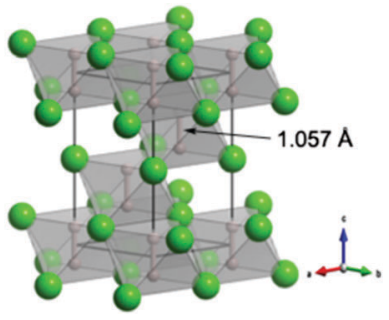

Fig. 4 Crystal structures of $\mathrm{H}_{2} \mathrm{Cl}$ in the (a) $\mathrm{C} 2 / \mathrm{c}$ and (b) $R \overline{3} \mathrm{~m}$ phases. 


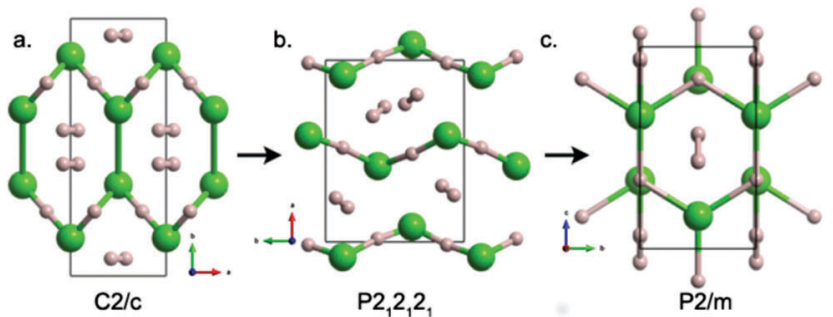

Fig. 5 Crystal structures of $\mathrm{H}_{3} \mathrm{Cl}$ in the (a) $\mathrm{C} 2 / \mathrm{C}$, (b) $P 2_{1} 2_{1} 2_{1}$ and (c) $P 2 / m$ phases.

In $\mathrm{C} 2 / \mathrm{c}-\mathrm{H}_{3} \mathrm{Cl}$, the $\mathrm{HCl}$ units are also packed in symmetric zigzag chains, between which non-bonded $\mathrm{H}_{2}$ molecules are located - formally two $\left(\mathrm{H}_{2} \mathrm{Cl}_{2}\right)_{n}$ polymers and four $\mathrm{H}_{2}$ units per unit cell (Fig. 5a). The presence of $\mathrm{H}_{2}$ reduces the pressure required to symmetrize $\mathrm{H}$-bonds in the $\mathrm{Cl}-\mathrm{H}-\mathrm{Cl}$ chain in $C m c 2_{1}-\mathrm{HCl}$. The $C 2 / c$ structure can be viewed as a host-guest inclusion compound: a stacked 1D planar inorganic polymeric $\mathrm{HCl}$ chain with encapsulated $\mathrm{H}_{2}$ units in the van der Waals space. Symmetrization of the $\mathrm{HCl}$ chain occurs at $\sim 20 \mathrm{GPa}$, whereas in $\mathrm{HCl}$ it takes place at a much higher pressure of $\sim 50 \mathrm{GPa}$. Therefore, $\mathrm{H}_{2}$ dimers act by either adding extra mechanical pressure or through chemical doping in the symmetrization process, lowering the driving force of the Peierls instability.

Obviously, free rotation is allowed around the bonding $\mathrm{H}-\mathrm{Cl}$ chain, thus, a non-planar form may exist. In the higher-pressure $P 2_{1} 2_{1} 2_{1}$ phase (Fig. $5 \mathrm{~b}$ ), slightly helical zigzag $\mathrm{HCl}$ chains run along the $b$-axis. The dihedral angle $\mathrm{H}-\mathrm{Cl}-\mathrm{Cl}-\mathrm{H}$ is $14.1^{\circ}$ at $100 \mathrm{GPa}$. There are four $\mathrm{H}_{2}$ dimers per unit cell located in the cavities between two slightly helical chains. Above $271 \mathrm{GPa}$, a $P 2 / m$ structure is stable (Fig. 5c). One can observe graphene-like arrays formed together by $\mathrm{Cl}$ and $\mathrm{H}$ atoms, some parallel and some perpendicular to the ac plane. The graphene-like nets are composed by the staggered packing of symmetric $\mathrm{HCl}$ zigzag chains. $\mathrm{H}_{2}$ units are observed in channels formed by graphene-like nets.

\section{3 $\mathrm{H}_{5} \mathrm{Cl}$ : the existence of $\mathrm{H}_{3}{ }^{+}$and $\mathrm{H}_{5}{ }^{+}$units}

The crystal structures of $\mathrm{H}_{5} \mathrm{Cl}$ phases are shown in Fig. 6. The low-pressure $P C$ structure contains planar chains composed of triangular $\mathrm{H}_{3}$ units connected to two $\mathrm{Cl}$ atoms. The structure also contains isolated $\mathrm{H}_{2}$ dimers $(\mathrm{H}-\mathrm{H}=0.748 \AA$ at $150 \mathrm{GPa})$. Formally, the $\mathrm{H}_{3}$ unit may be viewed as the well-known $\mathrm{H}_{3}{ }^{+}$ cation interacting with one $\mathrm{Cl}^{-}$anion. The $\mathrm{H}_{3}{ }^{+}$cation deviates slightly from an equilateral triangle $(\mathrm{H}-\mathrm{H}=0.864-0.913 \AA$ at $150 \mathrm{GPa}$ ), which is the shape experimentally and theoretically observed in the gas phase $\mathrm{H}_{3}{ }^{+}$for this smallest and simplest aromatic molecule. ${ }^{41}$ The $\mathrm{H}-\mathrm{H}$ bond lengths are elongated by $19 \%$ relative to the calculated distance in encapsulated $\mathrm{H}_{2}$ dimers or the experimental free gas $\mathrm{H}_{2}(0.74 \AA)$. Such elongation is expected for an electron-deficient system (Fig. 6c). The stability of $\mathrm{H}_{3}{ }^{+}$can be attributed to the occupation of the $\mathrm{a}_{1}{ }^{\prime}$ bonding molecular orbital (MO) and the large HOMO $\mathrm{a}_{1}{ }^{\prime}$-LUMO $\mathrm{e}^{\prime}$ gap. The formal $\mathrm{H}-\mathrm{H}$ bond order is $1 / 3$ per $\mathrm{H}-\mathrm{H} \operatorname{link}\left(1\right.$ in $\left.\mathrm{H}_{2}\right)$, explaining the longer $\mathrm{H}-\mathrm{H}$ distances for $\mathrm{H}_{3}{ }^{+}\left(\mathrm{H}_{3}{ }^{+}\right.$can be described by the well-known three-center two-electron bonding

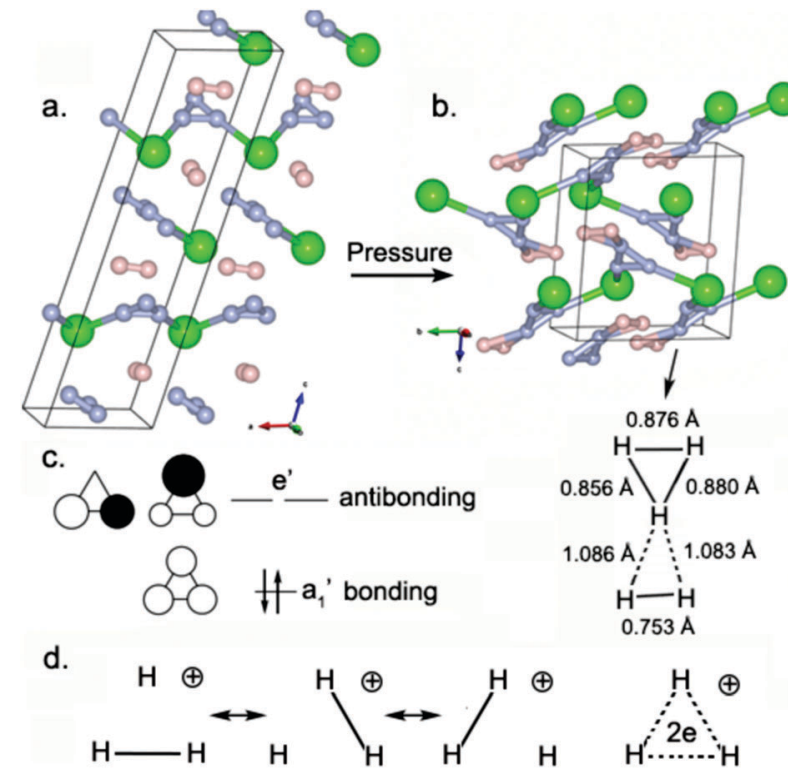

Fig. 6 Crystal structures of $\mathrm{H}_{5} \mathrm{Cl}$ in the (a) $P C$ phase at $150 \mathrm{GPa}$ and (b) $P 2_{1} / c$ phase at $350 \mathrm{GPa}$. (c and d) Molecular orbital diagram and Lewis structures for the $\mathrm{H}_{3}{ }^{+}$cation.

scheme). $\mathrm{H}_{3}{ }^{+}$is stabilized in this solid-state compound by electrostatic interactions with the anionic chloride network.

$\mathrm{H}_{2}$ acts as an electron donor in combination with a proton to yield $\mathrm{H}_{3}{ }^{+}$. By analogy, $\mathrm{H}_{2}$ may also combine with $\mathrm{H}_{3}{ }^{+}$, leading to the higher homolog $\mathrm{H}_{5}{ }^{+}$(Fig. S7, ESI $\dagger$ ). The existence of $\mathrm{H}_{3}{ }^{+}$and $\mathrm{H}_{5}{ }^{+}$has been firmly established by mass spectrometry and quantum-mechanical calculations. ${ }^{41-44}$ In fact, gas phase charged hydrogen clusters are a well-known stable species, provided that the number of hydrogen atoms is odd. ${ }^{45,46}$ The $\mathrm{H}_{5}{ }^{+}$ion appears in the high-pressure $P 2_{1} / c$ phase of $\mathrm{H}_{5} \mathrm{Cl}$. The $\mathrm{H}-\mathrm{H}$ distances reveal the existence of the planar $\mathrm{H}_{5}{ }^{+}$unit: all $\mathrm{H}-\mathrm{H}$ distances are in the range of $0.753-1.086 \AA$ at $350 \mathrm{GPa}$. In the pseudoequilateral $\mathrm{H}_{3}$ unit, the $\mathrm{H}-\mathrm{H}$ bond lengths are $0.856-0.880 \AA$. Two $\mathrm{H}-\mathrm{H}$ bonds are significantly longer (1.083-1.086 $\mathrm{A})$ than the $\mathrm{H}-\mathrm{H}$ bonds reported in $\mathrm{H}_{3}$ units, indicating weaker bonds. The shortest distance is $0.753 \AA$, similar to the length of the $\mathrm{H}-\mathrm{H}$ covalent bond in free $\mathrm{H}_{2}$ gas. Therefore, this planar $\mathrm{H}_{5}$ unit may be viewed as $\mathrm{H}_{3}{ }^{+}$interacting with a slightly activated $\mathrm{H}_{2}$ dimer. A five-center four-electron bonding scheme is assigned: such a bonding mode has been previously observed in protonated hydrogen-based clusters, ${ }^{47}$ the global-minimum structure of which is, however, non-planar. The calculated electronic properties show that this compound is an insulator up to $400 \mathrm{GPa}$ (Fig. S5, ESI $\dagger$ ). Obviously, a hydrogen-rich system is not more easily metallized than a chlorine-rich system.

\section{4 $\mathrm{H}_{4} \mathrm{Cl}_{7}$ : chlorine-based Kagomé layers intercalated with zigzag $\mathrm{HCl}$ chains}

Besides H-rich $\mathrm{H}_{x} \mathrm{Cl}_{y}$ compounds, we also uncovered a Cl-rich compound $\mathrm{H}_{4} \mathrm{Cl}_{7}$, which has never been reported before. $\mathrm{H}_{4} \mathrm{Cl}_{7}$ has two structures in the pressure range 0-400 $\mathrm{GPa}$, i.e. $\mathrm{C} 2 / \mathrm{m}$ (87-280 GPa) and $C 2(280-400 \mathrm{GPa})$. In the low-pressure $C 2 / m$ 
phase (Fig. 7a), two different networks can be found, namely two $(\mathrm{HCl})_{2}$ zigzag chains intercalated between planar Kagomé $\left(\mathrm{Cl}_{3}\right)_{2}$ covalent layers $\left(4 \mathrm{H}_{2} \mathrm{Cl}_{2}+2 \mathrm{Cl}_{3}=\mathrm{H}_{8} \mathrm{Cl}_{14}\right)$. The $1 \mathrm{D}$ zigzag chain has the topology encountered in the $\mathrm{Cmcm}-\mathrm{HCl}$ phase with two-coordinate bent chlorine atoms and two-coordinate (almost) linear hydrogens $\left(\mathrm{Cl}-\mathrm{H}=1.46-1.47 \AA\right.$ А $\mathrm{H}-\mathrm{Cl}-\mathrm{H}=98.7^{\circ}$; $\left.\mathrm{Cl}-\mathrm{H}-\mathrm{Cl}=173.5^{\circ}\right)$. Besides, the $C 2 / m$ structure contains a $2 \mathrm{D}$ hexagonal network of chlorine atoms comprising triangles and hexagons, shown in Fig. 7b. The planar Kagomé $\left(\mathrm{Cl}_{3}\right)_{2}$ covalent layers possess four-coordinate (with rectangular planar coordination) chlorine atoms with $\mathrm{Cl}-\mathrm{Cl}$ bond distances of 2.236-2.273 $\AA$ and bond angles of $60.5^{\circ}$ and $119.5^{\circ}$ at $100 \mathrm{GPa}$. Seven electrons may be formally assigned to each chlorine atom, thus according to the VSEPR model, the chlorine atom is the $\mathrm{AX}_{4} \mathrm{E}_{3 / 2}$ type, a rectangular planar $\mathrm{AX}_{4}$ unit (one electron less than that of $\mathrm{XeF}_{4}{ }^{48}$ ).

The high-pressure $C 2$ phase has even more complex substructures (Fig. 8a). First, the 2D Kagomé chlorine (3636) layers found in the low-pressure $C 2 / m$ phase still exist $(\mathrm{Cl}-\mathrm{Cl}=2.146-$ $2.162 \AA$ at $350 \mathrm{GPa}$ ). Second, between these planar Kagomé layers, there are two zigzag $(\mathrm{HCl})_{2}$ chains with two types of coordinated chlorine atoms: one is coordinated to two bridging hydrogen atoms $(\mathrm{H}-\mathrm{Cl}=1.367-1.387 \AA)$, the other is four-coordinated to two bridging hydrogen atoms $(\mathrm{H}-\mathrm{Cl}=$ 1.375-1.379 $\AA$ ) and two chlorine atoms through short and long bonds $(\mathrm{Cl}-\mathrm{Cl}=2.051-2.223 \AA)$. Finally, one may see $1 \mathrm{D}$ linear chlorine chains running through the center of $\mathrm{Cl}_{6}$ hexagons
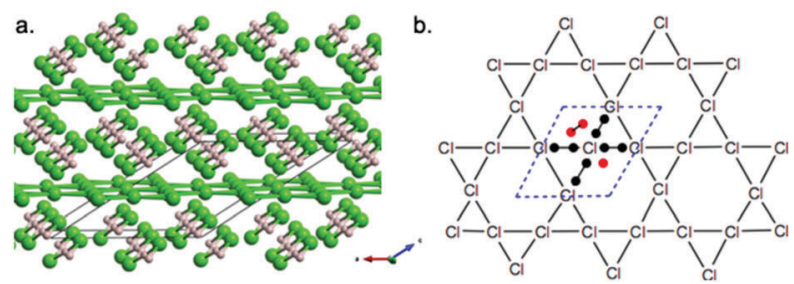

Fig. 7 (a) Crystal structure of $\mathrm{C} 2 / \mathrm{m}-\mathrm{H}_{4} \mathrm{Cl}_{7}$ at $100 \mathrm{GPa}$. (b) VSEPR analysis of the planar Kagomé $\left(\mathrm{Cl}_{3}\right)_{2}$ covalent layers.

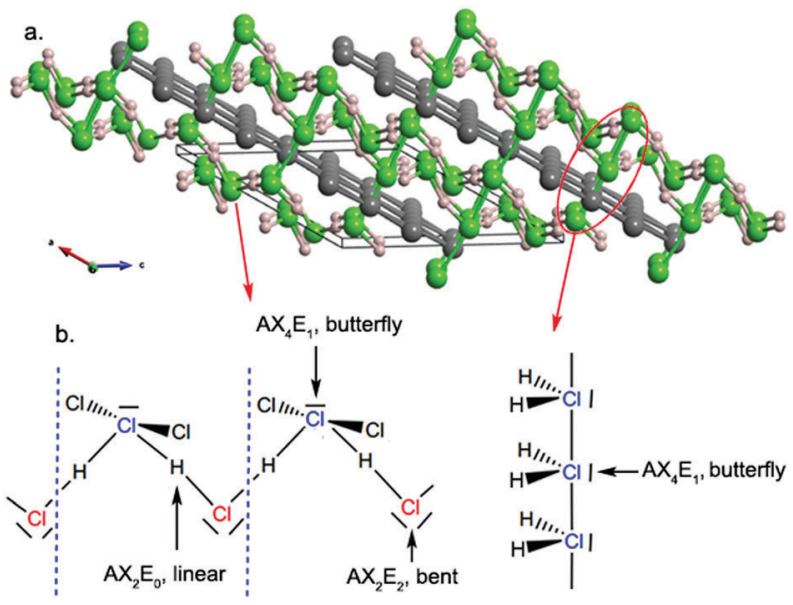

Fig. 8 (a) Crystal structure of $\mathrm{C}_{2}-\mathrm{H}_{4} \mathrm{Cl}_{7}$ at $350 \mathrm{GPa}$. The chlorine-based Kagomé layers are drawn in grey color. (b) VSEPR analyses of the zigzag $\mathrm{HCl}$ chain (left) and the linear chlorine one (right) in the C2 phase. with alternating distances (2.006 ̊̊ and 2.183 ̊̊). Even though this phase displays delocalized bonding (e.g. the $\mathrm{Cl}-\mathrm{Cl}$ long distance of $2.223 \AA$, signature of an electron-deficient covalent bond), its local structures are rationalized by using VSEPR rules from single Lewis resonant structures (Fig. 8b and Fig. S8, ESI $\dagger$ ). For the $1 \mathrm{D}$ zigzag $(\mathrm{HCl})_{2}$ chains, the two-coordinate chlorine atoms are $\mathrm{AX}_{2} \mathrm{E}_{2}$ type with a bent geometry $\left(\mathrm{H}-\mathrm{Cl}-\mathrm{H}=99.2^{\circ}\right)$. The four-coordinate chlorine atoms are $\mathrm{AX}_{4} \mathrm{E}_{1}$ type with a local butterfly-like structure $\left(\mathrm{H}-\mathrm{Cl}-\mathrm{H}=92.3^{\circ}, \mathrm{Cl}-\mathrm{Cl}-\mathrm{Cl}=172.4^{\circ}\right)$. The two-coordinate hydrogen atom is $\mathrm{AX}_{2} \mathrm{E}_{0}$ type with a (almost) linear geometry. DFT calculations show that both $\mathrm{C} 2 / \mathrm{m}$ - and $C 2-\mathrm{H}_{4} \mathrm{Cl}_{7}$ phases are metallic, mainly due to the Cl-p states.

\section{Conclusion}

In summary, we have extensively explored the stable stoichiometries and structures in the $\mathrm{H}-\mathrm{Cl}$ system up to $400 \mathrm{GPa}$. Besides $\mathrm{HCl}$, we also discovered three hydrogen-rich compounds, $\mathrm{H}_{2} \mathrm{Cl}, \mathrm{H}_{3} \mathrm{Cl}$ and $\mathrm{H}_{5} \mathrm{Cl}$, and a chlorine-rich compound $\mathrm{H}_{4} \mathrm{Cl}_{7}$. $\mathrm{HCl}$ and $\mathrm{H}_{3} \mathrm{Cl}$ show reentrant behavior. With increasing pressure, they will first decompose into adjacent stoichiometries, then become stable at a higher pressure again. Our results show that the ZPE contribution to the total energy will significantly affect the stability of $\mathrm{H}_{x} \mathrm{Cl}_{y}$ compounds. After considering ZPE corrections, $P 4 / n m m$-HCl has lower enthalpy than the previously proposed $C 2 / m$ structure, and $C 2 / c-\mathrm{H}_{3} \mathrm{Cl}$ has a lower enthalpy than the $C c$ structure proposed by Duan et al. Besides, we found a Pc structure for $\mathrm{H}_{5} \mathrm{Cl}$ at low pressures, which is more energetically favorable than the $C c$ structure. And $\mathrm{H}_{7} \mathrm{Cl}$ is metastable with or without $\mathrm{ZPE}$ correction in the whole studied pressure range.

The newly discovered $\mathrm{H}_{x} \mathrm{Cl}_{y}$ compounds possess peculiar structural characteristics and rich chemical bonding types. Here, we used VSEPR and molecular orbital theory to rationalize their formation. The zigzag shape of $\mathrm{H}-\mathrm{Cl} \cdots \mathrm{H}-\mathrm{Cl}$ chains can be explained by the Lewis acid model based on electrostatic potential calculations. Under high pressure, asymmetric zigzag chains become symmetric. In $\mathrm{H}_{5} \mathrm{Cl}$, triangular $\mathrm{H}_{3}{ }^{+}$cations are stabilized by electrostatic interactions with the anionic chloride network. Further increase of pressure makes $\mathrm{H}_{2}$ dimers combine with $\mathrm{H}_{3}{ }^{+}$ cations to form $\mathrm{H}_{5}{ }^{+}$units. Additionally, we found chlorine-based Kagomé layers in $\mathrm{H}_{4} \mathrm{Cl}_{7}$, intercalated with zigzag $\mathrm{HCl}$ chains. These findings of unexpected complexity in the simple $\mathrm{H}-\mathrm{Cl}$ system will be helpful in understanding the effect of pressure on chemical bonding.

\section{Acknowledgements}

We thank the National Natural Science Foundation of China (Grants No. 51372203, 51332004 and 51571166), the Foreign Talents Introduction and Academic Exchange Program (Grant No. B08040), Poitiers University (mésocentre de calculs Thor) and CNRS, the Government of the Russian Federation (Grant No. 14.A12.31.0003), and the Fundamental Research Funds for the Central Universities of China (Grant No. 3102016JKBJJGZ02) for financial support. We also acknowledge the high performance 
computing center of NWPU (China), and TGCC/Curie GENCI (France) under project no. 2016087539 for allocation of computing time on their machines.

\section{References}

1 E. Wigner and H. B. Huntington, J. Chem. Phys., 1935, 3, 764-770.

2 W. Grochala, R. Hoffmann, J. Feng and N. W. Ashcroft, Angew. Chem., Int. Ed., 2007, 46, 3620.

3 E. Zurek and W. Grochala, Phys. Chem. Chem. Phys., 2015, 17, 2917-2934.

4 W. Zhang, A. R. Oganov, A. F. Goncharov, Q. Zhu, S. E. Boulfelfel, A. O. Lyakhov, E. Stavrou, M. Somayazulu, V. B. Prakapenka and Z. Konôpková, Science, 2012, 342, 1502-1505.

5 G. Saleh and A. R. Oganov, Phys. Chem. Chem. Phys., 2016, 18, 2840-2849.

6 N. W. Ashcroft, Phys. Rev. Lett., 1968, 21, 1748-1749.

7 D. Duan, Y. Liu, F. Tian, D. Li, X. Huang, Z. Zhao, H. Yu, B. Liu, W. Tian and T. Cui, Sci. Rep., 2014, 4, 6968.

8 A. P. Drozdov, M. I. Eremets, I. A. Troyan, V. Ksenofontov and S. I. Shylin, Nature, 2015, 525, 73-76.

9 N. W. Ashcroft, Phys. Rev. Lett., 2004, 92, 187002.

10 J. Obriot, F. Fondère, P. Marteau and M. Allavena, J. Chem. Phys., 1983, 79, 33-42.

11 L. Zhang, Y. Wang, X. Zhang and Y. Ma, Phys. Rev. B: Condens. Matter Mater. Phys., 2010, 82, 1558-1564.

12 C. Chen, Y. Xu, X. Sun and S. Wang, J. Phys. Chem. C, 2015, 119, 17039-17043.

13 H. Shimizu, K. Kamabuchi, T. Kume and S. Sasaki, Phys. Rev. B: Condens. Matter Mater. Phys., 1999, 59, 11727-11732.

14 K. Aoki, E. Katoh, H. Yamawaki, M. Sakashita and H. Fujihisa, Phys. B, 1999, 265, 83-86.

15 D. Duan, F. Tian, Z. He, X. Meng, L. Wang, C. Chen, X. Zhao, B. Liu and T. Cui, J. Chem. Phys., 2010, 133, 074507.

16 Z. Wang, H. Wang, J. S. Tse, T. Iitaka and Y. Ma, Chem. Sci., 2014, 6, 522-526.

17 D. Duan, X. Huang, F. Tian, Y. Liu, D. Li, H. Yu, B. Liu, W. Tian and T. Cui, J. Phys. Chem. A, 2015, 119, 11059-11065.

18 A. R. Oganov and C. W. Glass, J. Chem. Phys., 2006, 124, 244704.

19 A. O. Lyakhov, A. R. Oganov, H. T. Stokes and Q. Zhu, Comput. Phys. Commun., 2013, 184, 1172-1182.

20 A. R. Oganov, A. O. Lyakhov and M. Valle, Acc. Chem. Res., 2011, 44, 227-237.
21 G. Kresse and J. Furthmüller, Comput. Mater. Sci., 1996, 6, 15-50.

22 J. P. Perdew, K. Burke and M. Ernzerhof, Phys. Rev. Lett., 1996, 77, 3865-3868.

23 P. E. Blöchl, Phys. Rev. B: Condens. Matter Mater. Phys., 1994, 50, 17953-17979.

24 G. Kresse and D. Joubert, Phys. Rev. B: Condens. Matter Mater. Phys., 1999, 59, 1758.

25 A. Togo, F. Oba and I. Tanaka, Phys. Rev. B: Condens. Matter Mater. Phys., 2008, 78, 134106.

26 R. A. Kendall, T. H. Dunning and R. J. Harrison, J. Chem. Phys., 1992, 96, 6796-6806.

27 E. R. Davidson, Chem. Phys. Lett., 1996, 260, 514-518.

28 M. J. Frisch, G. W. Trucks, H. B. Schlegel, G. E. Scuseria and M. A. Robb, et al., Gaussian, 2001.

29 F. A. Bulat, A. Toro-Labbé, T. Brinck, J. S. Murray and P. Politzer, J. Mol. Model., 2010, 16, 1679-1691.

30 C. J. Pickard and R. J. Needs, Nat. Phys., 2007, 3, 473-476.

31 P. Li, G. Gao and Y. Ma, J. Chem. Phys., 2012, 137, 2840-2847.

32 A. Bondi, J. Phys. Chem., 1964, 68, 441-451.

33 G. Bao, D. Duan, D. Zhou, X. Jin, B. Liu and T. Cui, J. Phys. Chem. B, 2010, 114, 13933-13939.

34 G. Bao, D. Duan, F. Tian, L. Wang, B. Liu and T. Cui, J. Chem. Phys., 2011, 134, 123-127.

35 T. Clark, M. Hennemann, J. S. Murray and P. Politzer, J. Mol. Model., 2007, 13, 291-296.

36 T. Clark, Wiley Interdiscip. Rev.: Comput. Mol. Sci., 2013, 3, 13-20. 37 Y. Duan and D. C. Sorescu, J. Chem. Phys., 2010, 133, 304-311.

38 P. Li, G. Gao and Y. Ma, J. Chem. Phys., 2012, 137, 2840-2847.

39 A. Simon, Angew. Chem., Int. Ed. Engl., 1997, 36, 1788-1806.

40 P. B. Allen and R. C. Dynes, Phys. Rev. B: Solid State, 1975, 12, 905-922.

41 R. D. Poshusta and F. A. Matsen, J. Chem. Phys., 1967, 47, 4795-4799.

42 J. J. Thomson, J. Rönt. Soc., 1922, 18, 150-151.

43 R. E. Christoffersen, J. Chem. Phys., 1964, 41, 960-971.

44 P. H. Dawson and A. W. Tickner, J. Chem. Phys., 1962, 37, 672-673.

45 H. Chermette and I. Ymmud, Phys. Rev. B: Condens. Matter Mater. Phys., 2001, 63, 165427.

46 M. Farizon, B. Farizon-Mazuy, N. de Castro Faria and H. Chermette, Chem. Phys. Lett., 1991, 177, 451-457.

47 I. Štich, D. Marx, M. Parrinello and K. Terakura, J. Chem. Phys., 1997, 107, 9482-9492.

48 Q. Zhu, D. Y. Jung, A. R. Oganov, C. W. Glass, C. Gatti and A. O. Lyakhov, Nat. Chem., 2013, 5, 61-65. 